\title{
Efisiensi Pemasaran Lanting Di Desa Karang Anyar Kecamatan Gedong Tataan Kabupaten Pesawaran
}

\section{The Efficiency of Lanting's Marketing at Karang Anyar Village, Gedong Tataan, Pesawaran}

\author{
Real Irhamna $^{1 *}$, Marlinda Apriyani ${ }^{1}$, Dan Irmayani Noer ${ }^{1}$ \\ ${ }^{1}$ Politeknik Negeri Lampung \\ *E-mail: hamnareal06@gmail.com
}

\begin{abstract}
Karanganyar Village, Gedong Tataan Subdistrict, Pesawaran Regency, has several marketing channels for lanting products, thus making this study analyze the efficiency of lanting marketing. The research method used is a survey method, namely a research method by using a questionnaire as a research tool in large and small populations, but the data studied is data from samples taken from that population. This research was conducted in Karanganyar Village, Gedong Tataan District, Pesawaran Regency, with 37 respondents using the snowball sampling method. The analysis used is marketing channels, marketing margins, business profits, and marketing efficiency of lanting product prices. The results of the analysis show that the most efficient marketing of lanting is a marketing channel that does not involve a marketing agency in it, namely producers directly to the final consumer. This marketing channel is the first channel (channel 1).
\end{abstract}

Keywords: efficiency, lanting, and marketing

Disubmit: 25 Februari 2021; Diterima: 23 Maret 2021; Disetujui: 26 April 2021

\section{PENDAHULUAN}

Usaha Mikro Kecil Menengah (UMKM) merupakan sebuah usaha yang dilakukan oleh seseorang atau individu baik berupa kerajinan tangan maupun olahan hasil-hasil pertanian. Produk olahan hasil pertanian misalnya keripik pisang, keripik ubi jalar, marning jagung, keripik singkong, lanting dan lain sebagainya. Salah satu produk pertanian yang diolah menjadi olahan pangan yaitu ubi kayu. Provinsi Lampung adalah salah satu sentra penghasil ubi kayu terbesar di Indonesia. Jumlah produksi ubi kayu per tahunnya rata-rata mencapai 7.136.599 ton.

Kabupaten Pesawaran merupakan salah satu lokasi Usaha Mikro Kecil Menengah (UMKM) yang memproduksi olahan pangan berbasis komoditas pertanian. Agroindustri yang ada di Kabupaten Pesawaran merupakan suatu pemanfaatan hasil pertanian menjadi produk olahan yang memiliki nilai ekonomi yang tinggi. Data - data mengenai jumlah pelaku usaha mikro kecil menengah (UMKM) yang ada di Kabupaten Pesawaran dapat di sajikan pada Tabel 1.

Tabel 1. Data pelaku UMKM Kabupaten Pesawaran tahun 2020

\begin{tabular}{clc}
\hline \multicolumn{1}{c}{ Kecamatan } & Jumlah \\
\hline No. & Gedong Tataan & 393 \\
2. & Tegineneng & 599 \\
3. & Negeri Katon & 126 \\
\hline
\end{tabular}




\begin{tabular}{clc}
\hline 4. & Kedondong & 572 \\
5. & Way Lima & 252 \\
6. & Way Khilau & 144 \\
7. & Punduh Pidada & 301 \\
8. & Marga Punduh & 841 \\
9. & Padang Cermin & 176 \\
10. & Teluk Pandan & 167 \\
11. & Way Ratai & 235 \\
\hline & & 3.806 \\
\hline
\end{tabular}

Sumber: Dinas Koperasi dan UMKM, 2020

Tabel 1 menujukkan jumlah Usaha Mikro Kecil Menengah (UMKM) yang ada di Kabupaten Pesawaran pada setiap kecamatan menunjukkan jumlah yang berbeda-beda, Kecamatan Gedong Tataan memiliki jumlah UMKM terbanyak keempat sebagai sentra industri pelaku Usaha Mikro Kecil Menengah (UMKM) yaitu terdapat 393 pelaku Usaha.

Produk olahan berbahan dasar ubi kayu khususnya produk lanting memiliki jumlah pelaku usaha atau UMKM paling banyak yaitu sebanyak 40 UMKM yang memproduksi lanting (Balai Desa Karanganyar, 2018). Pemasaran yang tepat dapat meningkatkan pendapatan para produsen dan lembaga mata rantai penyaluran produk lanting. Pemasaran merupakan suatu proses sosial dan manajerial yang menyebabkan para individu dan kelompok dapat menciptakan, menawarkan dan bertukar sesuatu yang memiliki nilai satu sama lain untuk mendapatkan kebutuhan dan keinginan konsumen (Boneta, 2013).

Efisiensi merupakan suatu usaha atau kegiatan yang dapat menghasilkan output atau luaran dengan menggunakan input-input tertentu untuk mendapatkan output semaksimal mungkin (Mahdalena, 2016). Permasalahan pada saluran pemasaran produk olahan lanting yaitu panjangnya saluran pemasaran. Hal ini sangat menguntungkan bagi lembaga penyalur, sehingga menyebabkan tingginya harga yang diterima oleh konsumen tingkat akhir. Semakin banyak lembaga penyalur di dalamnya maka semakin tinggi pula harga yang diterima oleh konsumen.

Tingkat efisiensi pemasaran lanting dapat diketahui dengan mengetahui margin pemasaran. Penelitian ini sangat berguna bagi para pengambil keputusan ataupun bagi para pelaku usaha dalam menentukan pemasaran produk agar terciptanya pemasaran produk yang efisien. Adapun tujuan dalam penelitian ini yaitu Analisis efisiensi pemasaran lanting di Desa Karanganyar Kecamatan Gedong Tataan Kabupaten Pesawaran.

\section{METODE PENELITIAN}

Penelitian ini di laksanakan di Desa Karanganyar Kecamatan Gedongtataan Kabupaten Pesawaran. Pelaksanaan penelitian dilakukan pada bulan bulan Mei 2019 hingga bulan September 2020.

Jenis penelitian ini merupakan penelitian survei yang dilakukan di Desa Karang Anyar Kecamatan Gedongtataan Kabupaten Pesawaran. Metode survey merupakan metode penelitian dengan cara menggunakan angket sebagai alat penelitian pada populasi besar maupun kecil, tetapi data yang dipelajari adalah data dari sampel yang diambil dari populasi tersebut (Sugiyono, 2013).

Metode pengambilan sampel produsen lanting dilakukan secara stratifikasi (stratified random sampling) dengan jenis non proportional stratified random sampling yaitu persentase sampel diambil setiap lapisan tidak sama. Hal ini dikarenakan produsen lanting memiliki nilai omset per tahun yang berbeda maka presentasi sampel yang diambil berbeda berdasarkan besarnya nilai omset per tahun (Sukandarrumidi, 2008). Secara lengkap pengelompokan pelaku usaha berdasarkan omset per tahun dapat dijelaskan pada Tabel 2. 
Tabel 2. Omset per tahun pelaku usaha industri rumahan yang memproduksi makanan ringan di Desa Karanganyar Kecamatan Gedong Tataan dan penentuan sampel responden, 2018

\begin{tabular}{ccccc}
\hline No. & Omset pertahun (juta rupiah) & Jumlah pelaku usaha & Persentase sampel (\%) & Jumlah sampel \\
\hline 1. & $>20$ & 18 & 15 & 3 \\
2. & $<20$ & 22 & 10 & 2 \\
\hline & Jumlah & 40 & 25 & 5 \\
\hline
\end{tabular}

Sumber: Balai Desa Karang Anyar, 2018

Tabel 2 menjelaskan bahwa strata atau lapisan yang digunakan dalam penelitian ini berdasarkan omset pertahun yang diperoleh, sehingga diperoleh sampel total sampel yang digunakan pada penelitian ini sebanyak 5 pelaku usaha lanting.

Pengambilan sampel lembaga pemasaran menggunakan teknik bola salju (snowball sampling) (Sukandarrumidi, 2008). Penentuan sampel lembaga pemasaran dengan teknik bola salju (snowball sampling) ditetapkan jumlah sampel sebagai berikut:

1. Pedagang pengepul tingkat desa sebanyak 2 pengepul

2. Pedagang pengecer sebanyak 10 orang pengecer

3. Konsumen yang membeli produk lanting sebanyak 20 orang

Pemilihan responden ini untuk memperoleh data primer dengan menggunakan kuessioner yang dibagikan kepada setiap responden. Metode analisis data yang dipergunakan untuk menjawab tujuan penelitian yaitu mengetahui Efisiensi Pemasaran Lanting di Desa Karang Anyar Kecamatan Gedongtataan Kabupaten Pesawaran yatu:

1. Saluran pemasaran lanting dianalisis secara kualitatif (deskriptif) dari produsen lanting hingga ke kkonsumen akhir pada setiap lembaga pemasaran yang terlibat.

2. Pangsa produsen (PS) berguna untuk mengetahui bagian harga yang diterima produsen. Apabila PS semakin tinggi, harga suatu komoditas pada suatu tingkat lembaga pemasaran dipengaruhi oleh harga di tingkat lembaga lainnya (Khairunnisa, Affandi and Suryani, 2018). Pangsa produsen dirumuskan sebagai berikut.

$$
\mathrm{PS}=\frac{\mathrm{PF}}{\mathrm{PR}} \times 100
$$

Keterangan :

Ps = Bagian harga lanting yang diterima produsen

Pf $=$ Harga lanting di tingkat produsen

$\operatorname{Pr}=$ Harga lanting di tingkat konsumen

Analisis margin pemasaran produk lanting dapat dirumuskan sebagai berikut (Sutarno, 2014):

$\mathrm{M}=\mathrm{Pr}-\mathrm{Pf}$

Keterangan :

$\mathrm{M} \quad=$ margin pemasaran

$\operatorname{Pr}=$ harga di tingkat pengecer (retail price)

Pf = harga di tingkat produsen (farm gate price)

Efisiensi pemasaran (Ep) dapat diukur dengan rumus sebagai berikut (Zuraida and Wahyuningsih, 2015):

$E p=\frac{\text { biaya pemasaran }}{\text { Nilai produk yang dipasarkan }} \times 100 \%$ 


\section{HASIL DAN PEMBAHASAN}

\section{Saluran Pemasaran}

Saluran pemasaran lanting yang teribat dapat dijelaskan pada Gambar 1.

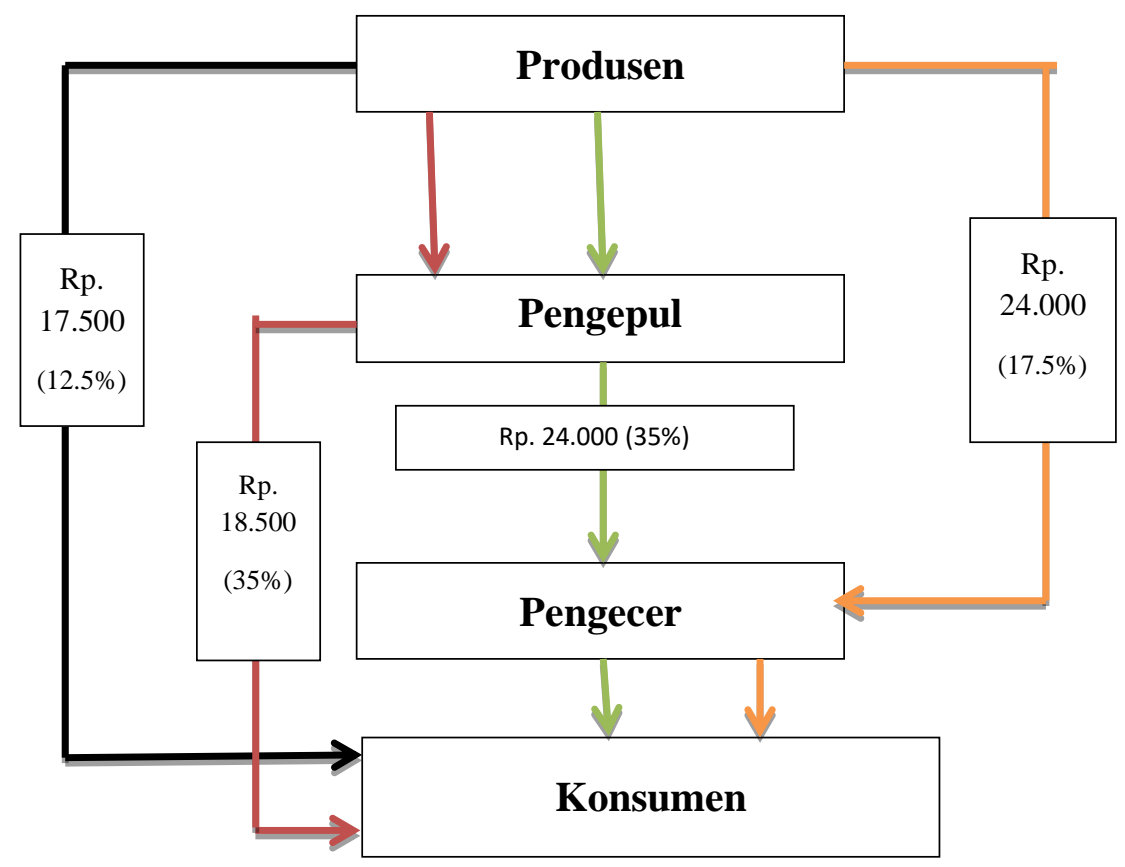

Gambar 1. Saluran pemasaran pada produk lanting di Desa Karang Anyar

Keterangan :
a. Saluran pemasaran 1 : garis hitam
b. Saluran pemasaran 2 : garis kuning
c. Saluran pemasaran 3 : garis merah $(\longrightarrow)$
d. Saluran pemasaran 4 : garis hijau (

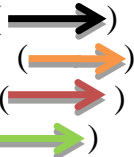

Gambar 1 menunjukkan bahwa terdapat empat saluran pemasaran yang ada di Desa Karang Anyar Kecamatan Gedong Tataan Kabupaten Pesawaran. Setiap saluran pemasaran yang terlibat memiliki jumlah persentase berbeda-beda, persentase pada saluran pemasaran ini mengacu pada jumlah produsen yang terlibat pada saluran pemasaran. Dilihat pada Gambar 1 saluran pemasaran ketiga dan keempat memiliki jumlah persentase yang imbang antara keduanya yaitu masing-masing 35\%, hal ini disebabkan antara produsen dengan pedagang pengepul kebanyakan sudah menjalin kerjasama anatara keduanya. Kerja sama ini berupa pinjaman modal berupa alat penunjang produksi ataupun penyediaan bahan baku berupa singkong. Saluran pemasaran kedua memiliki jumlah persentase $17.5 \%$ dan saluran pemasaran pertama memiliki jumlah persentase sebesar $12.5 \%$ hal ini dilakukan oleh produsen yang langsung menjual produk lanting tanpa melalui perantara pedagang pengepul. Mereka beranggapan bahwa harga yang didapatkan dari pedagang pengepul cenderung lebih sedikit dibandingkan dengan menjual langsung ke pengecer ataupun konsumen akhir, padahal keuntungan bekerjasama dengan pedagang pengepul yaitu mendapatkan pinjaman modal berupa alat penunjang produksi ataupun penyediaan bahan baku berupa singkong. Penentuan harga lanting ditingkat pedagang perantara khusus nya pengepul sudah ditentukan oleh pedagang perantara tersebut. Hambatan pasar pada produk lanting di Desa Karanganyar terjadi pada jangkauan pemasaran, luasnya jangkauan pemasaran jika menggunakan perantara pedagang pengepul. Maka dari itu produsen di Desa Karang Anyar lebih memilih menggunakan perantara pedagang pengepul dapat dilihat pada persentase gambar 1 diatas.

Konsumen akhir yang membeli di pasar pengecer pada pemasaran IV telah memperoleh selisih harga yang jauh dibandingkan dengan konsumen yang membeli langsung ke produsen lanting maupun pedagang 
perantara lainnya. Perbedaan harga yang terbentuk pada setiap saluran pemasaran lanting yang ada di Desa Karang Anyar dapat dilihat pada Tabel 3.

Tabel 3. Perbedaan harga yang terbentuk pada saluran pemasaran lanting

\begin{tabular}{ccccc}
\hline $\begin{array}{c}\text { Saluran } \\
\text { Distribusi }\end{array}$ & $\begin{array}{c}\text { Harga Tingkat Produsen } \\
(\mathrm{Rp} / \mathrm{kg})\end{array}$ & $\begin{array}{c}\text { Harga Tingkat } \\
\text { Pengepul }(\mathrm{Rp} / \mathrm{kg})\end{array}$ & $\begin{array}{c}\text { Harga Tingkat } \\
\text { Pengecer }(\mathrm{Rp} / \mathrm{kg})\end{array}$ & $\begin{array}{c}\text { Harga Tingkat } \\
\text { Konsumen }(\mathrm{Rp} / \mathrm{kg})\end{array}$ \\
\hline 1 & 17.500 & - & - & 17.500 \\
2 & 17.000 & - & 24.000 & 24.000 \\
3 & 14.000 & 18.500 & - & 18.500 \\
4 & 14.000 & 17.000 & 24.000 & 24.000 \\
\hline
\end{tabular}

Sumber: Data primer diolah, 2020.

Tabel 3 menyatakan bahwa terdapat perbedaan harga yang cukup jauh terjadi pada saluran pemasaran ke empat yang menggunakan seluruh lembaga pemasaran, yaitu konsumen akhir harus membayar Rp24.000/kg untuk membeli produk lanting.

\section{Margin Pemasaran dan Keuntungan Usaha Lanting}

Analisis margin pemasaran dan keuntungan usaha lanting yang di produksi oleh masyarakat Desa Karang Anyar Kecamatan Gedongtataan tentunya dapat diketahui bersama pada penjelasan berikut.

\section{Analisis margin pemasaran usaha lanting}

Menurut Istiyanti et al., (2015) Marjin pemasaran merupakan selisih harga di tingkat produsen dengan harga yang dibayarkan oleh konsumen akhir. Besarnya marjin pada setiap saluran pemasaran dipengaruhi oleh banyaknya lembaga atau pedagang perantara yang terlibat didalamnya, adapun perhitungan margin pemasaran didapatkan dari pengurangan biaya penjualan dengan biaya pembelian pada setiap tingkat lembaga pemasaran (Fitri, Apriyani and Sari, 2017). Analisis margin pemasaran dihitung untuk mengetahui besaran keuntungan pada setiap saluran pemasaran lanting dapat dilihat pada Tabel 4.

Tabel 4 menjelaskan margin pemasaran tertinggi didapatkan oleh saluran pemasaran yang menjual produk lanting ke pedagang pengecer dengan total margin sebesar Rp. 13.686,-/kg. Margin pemasaran yang didapat dari setiap lembaga berbeda-beda, Tabel 18 menjelaskan total margin tertinggi terjadi pada saluran pemasaran kedua dan keempat yaitu sebesar Rp. 13.686,-/kg, sedangkan margin pemasaran yang paling kecil diperoleh pada saluran pemasaran pertama yaitu sebesar Rp. 7.186,-/kg.

Tabel 4. Margin pemasaran

\begin{tabular}{|c|c|c|c|c|c|}
\hline No & Uraian & Saluran $1(\mathrm{Rp} / \mathrm{kg})$ & Saluran $2(\mathrm{Rp} / \mathrm{kg})$ & Saluran $3(\mathrm{Rp} / \mathrm{kg})$ & Saluran $4(\mathrm{Rp} / \mathrm{kg})$ \\
\hline \multirow[t]{4}{*}{1} & Produsen & & & & \\
\hline & a. HPP & 10.314 & 10.314 & 10.314 & 10.314 \\
\hline & b. Harga Jual & 17.500 & 17.000 & 14.000 & 14.000 \\
\hline & Margin Pemasaran & 7.186 & 6.686 & 3.686 & 3.686 \\
\hline \multirow[t]{4}{*}{2} & Pedagang Pengepul & & & & \\
\hline & a. Harga Beli & - & - & 14.000 & 14.000 \\
\hline & Harga Jual & - & - & 18.500 & 17.000 \\
\hline & Margin Pemasaran & - & - & 4.500 & 3.000 \\
\hline \multirow[t]{4}{*}{3} & Pengecer & & & & \\
\hline & a. Harga Beli & - & 17.000 & - & 17.000 \\
\hline & b. Harga Jual & - & 24.000 & - & 24.000 \\
\hline & Margin Pemasaran & - & 7.000 & - & 7.000 \\
\hline \multirow[t]{2}{*}{4} & Konsumen akhir & & & & \\
\hline & a. Harga Beli & 17.500 & 24.000 & 18.500 & 24.000 \\
\hline \multicolumn{2}{|c|}{ Total Margin } & 7.186 & 13.686 & 8.186 & 13.686 \\
\hline
\end{tabular}

Sumber: Data primer diolah, 2020 


\section{Keuntungan usaha lanting}

Keuntungan merupakan pendapatan yang diperoleh produsen dari usaha memproduksi suatu produk yang dapat diketahui dari selisih penerimaan total dikurangi dengan biaya total (Heriani, Zakaria and Soelaiman, 2013). Menurut Istiyanti et al., (2015) Keuntungan pemasaran merupakan selisih antara marjin pemasaran dengan biaya pemasaran yang dikeluarkan oleh masing-masing lembaga pemasaran. Lembaga pemasaran tentunya menginginkan keuntungan yang lebih besar apabila biaya yang dikeluarkan juga besar. Suatu usaha dapat dikatakan memperoleh keuntungan jika biaya penerimaan lebih besar dari biaya yang dikeluarkan atau bisa disebut biaya produksi, berikut ini merupakan tabel rincian biaya penerimaan, biaya total dan keuntungan produksi lanting dapat dilihat pada Tabel 5.

Tabel 5. Rincian rata-rata penerimaan, biaya total, dan keuntungan produsen lanting

\begin{tabular}{clrr}
\hline No. & \multicolumn{1}{c}{ Uraian } & Nilai (Rp) & Persentase(\%) \\
\hline 1 & Penerimaan & 265.680 .000 & $100 \%$ \\
2 & Biaya Variabel & 171.172 .800 & $64.43 \%$ \\
3 & Biaya Tenaga Kerja & 34.579 .200 & $13.02 \%$ \\
4 & Biaya Kirim & 2.112 .000 & $0.79 \%$ \\
5 & Biaya Penyusutan & 1.139 .100 & $0.43 \%$ \\
\hline & Biaya Total & 209.291 .100 & $21.33 \%$ \\
\hline
\end{tabular}

Sumber: Data primer diolah, 2020.

Tabel 19 menjelaskan bahwa biaya total yang dikeluarkan oleh produsen dalam kurun waktu satu tahun yaitu sebesar Rp. 209.291.100,- dengan penerimaan yang diterima dari hasil penjualan lanting dalam kurun waktu satu tahun yaitu sebesar Rp. 265.680.000,- maka dari hasil perhitungan biaya penerimaan dikurangi dengan biaya total didapatkan hasil berupa keuntungan sebesar Rp. 56.676.900,- pertahun.

\section{Efisiensi pemasaran}

Efisiensi pemasaran lanting diukur dengan producer share yaitu perbandingan antara harga pada tingkat produsen dengan harga pada tingkat konsumen akhir dan rasio antara biaya pemasaran dengan nilai penjualan produk. Semakin besar nilai producer share dari produk lanting maka saluran pemasaran tersebut semakin efisien. Sebaliknya semakin kecil rasio antara biaya pemasaran yang dikeluarkan pada setiap lembaga pemasaran dengan nilai penjualan produk lanting maka saluran pemasaran tersebut semakin efisien (Istiyanti et al., 2015). Perhitungan producer share dan rasio antara biaya pemasaran dengan nilai penjualan produk dapat dijelaskan pada Tabel 20 dan Tabel 6.

Tabel 6. Producer share saluran pemasaran lanting di Desa Karang Anyar

\begin{tabular}{lccc}
\hline \multicolumn{1}{c}{ Saluran } & Harga Jual Produsen $(\mathrm{Rp} / \mathrm{Kg})$ & Harga Beli Konsumen $(\mathrm{Rp} / \mathrm{Kg})$ & Producer Share $(\%)$ \\
\hline Saluran I & 17.500 & 17.500 & 100 \\
Saluran II & 17.000 & 24.000 & 71 \\
Saluran III & 14.000 & 18.500 & 76 \\
Saluran IV & 14.000 & 24.000 & 58 \\
\hline
\end{tabular}

Sumber: data primer diolah, 2020

Berdasarkan Tabel 6 dapat diketahui bahwa saluran pemasaran yang paling efisien adalah saluran pemasaran pertama yaitu dari produsen ke konsumen akhir dengan nilai producer share paling besar yang mencapai $100 \%$ hal ini disebabkan harga jual produsen sama dengan harga beli konsumen akhir, kasus ini terjadi pada produsen yang menjual lanting langsung ke konsumen. 
Tabel 7. Rasio antara biaya pemasaran dengan nilai penjualan produk

\begin{tabular}{lccc}
\hline \multicolumn{1}{c}{ Saluran } & Biaya Pemasaran $(\mathrm{Rp} / \mathrm{Kg})$ & Nilai Penjualan $(\mathrm{Rp} / \mathrm{Kg})$ & Rasio $(\%)$ \\
\hline Saluran I & 566 & 17.500 & 3.23 \\
Saluran II & 1.985 & 24.000 & 8.27 \\
Saluran III & 677 & 18.500 & 3.66 \\
Saluran IV & 2.096 & 24.000 & 8.73 \\
\hline
\end{tabular}

Sumber: data primer diolah, 2020

Berdasarkan pada Tabel 7 untuk perhitungan rasio antara biaya pemasaran yang dikeluarkan pada setiap lembaga pemasaran dengan nilai penjualan produk lating, yang paling efisien berada pada saluran pertama yaitu produsen langsung ke konsumen akhir dengan rasio terkecil yang memiliki nilai $3.23 \%$ hal ini disebabkan karena biaya pemasaran yang dikeluarkan oleh produsen yaitu paling kecil dengan jumlah Rp.566/kg.

Alat analisis efisiensi pemasaran selain dari producer share dan rasio antara biaya pemasaran dengan nilai penjualan produk yaitu pangsa produsen, marjin, dan rasio marjin pemasaran yang dilakukan berdasarkan pada saluran pemasaran yang terlibat yaitu menggunakan empat saluran pemasaran. Hasil analisis pangsa produsen, marjin pemasaran, dan rasio profit marjin $(R P M)$ pada saluran pemasaran lanting dapat disajikan pada Tabel 8.

Tabel 8 menjelaskan bahwa keuntungan pedagang yang paling tinggi diperoleh pada saluran pemasaran kedua yaitu sebesar $\mathrm{Rp} 11.710,-/ \mathrm{kg}$ dan keuntungan pedagang terendah berada pada saluran pemasaran pertama yaitu Rp $6.620,-/ \mathrm{kg}$. Penetapan harga jual yang tinggi menghasilkan margin keuntungan yang tinggi. Wulandari, Qurniati and Herwati, (2018) yang menyatakan bahwa pedagang pengecer memperoleh keuntungan paling tinggi sedangkan produsen mendapatkan keuntungan yang paling rendah. Margin pemasaran paling tinggi berada pada saluran pemasaran kedua dan keempat dengan total Rp. $13.686 / \mathrm{kg}$ sedangkan margin pemasaran yang paling rendah berada pada saluran pemasaran pertama yaitu dengan jumlah Rp. 7.186/kg.

Nilai Rasio Profit Margin (RPM) diperoleh dari perbandingan margin keuntungan dengan biaya total. Nilai $R P M$ paling besar pada saluran pemasaran lanting dimiliki oleh saluran pemasaran pertama yaitu sebesar 11.69 artinya setiap Rp 1.00 biaya yang dikeluarkan untuk memasarkan produk lanting akan diperoleh keuntungan sebesar Rp 11.69. Analisis efisiensi menggunakan producer share yang paling besar yaitu berada pada saluran pemasaran pertama dengan jumlah 100\%, sedangkan dari pengukuran rasio antara biaya pemasaran dengan nilai penjualan produk yang memiliki nilai terkecil yaitu berada pada saluran pemasaran pertama dengan nilai $3.23 \%$.

Tabel 8. Pangsa Produsen, Marjin, dan RPM Pemasaran lanting pada saluran pemasaran

\begin{tabular}{|c|c|c|c|c|c|c|c|c|c|}
\hline \multirow{2}{*}{ No } & \multirow{2}{*}{ Uraian } & \multicolumn{2}{|c|}{ Saluran 1} & \multicolumn{2}{|c|}{ Saluran 2} & \multicolumn{2}{|c|}{ Saluran 3} & \multicolumn{2}{|c|}{ Saluran 4} \\
\hline & & $\mathrm{Rp} / \mathrm{Kg}$ & Share \% & $\mathrm{Rp} / \mathrm{Kg}$ & Share $\%$ & $\mathrm{Rp} / \mathrm{Kg}$ & Share \% & $\mathrm{Rp} / \mathrm{Kg}$ & Share\% \\
\hline 1 & Produsen & & & & & & & & \\
\hline & a. HPP & 10.314 & 58.94 & 42.98 & 42.98 & 10.314 & 55.75 & 10.314 & 42.98 \\
\hline & b. Harga jual & 17.500 & 100 & 70.83 & 70.83 & 14.000 & 75.68 & 14.000 & 58.33 \\
\hline & c. Biaya pengemasan & 566 & 3.23 & 2.36 & 2.36 & 566 & 3.06 & 566 & 2.36 \\
\hline & d. Margin pemasaran & 7.186 & 41.06 & 27.86 & 27.86 & 3.686 & 19.92 & 3.686 & 15.36 \\
\hline & e. Margin keuntungan & 6.620 & 37.83 & 27.86 & 25.50 & 3.120 & 16.86 & 3.120 & 13.00 \\
\hline & f. Rasio profit margin & 11.69 & & 25.50 & & 5.51 & & 5.51 & \\
\hline 2 & Pedagang Pengepul & & & & & & & & \\
\hline & a. Harga & & & & & 14.000 & 75.68 & 14.000 & 58.33 \\
\hline & b. Biaya kirim & & & & & 111 & 0.60 & 111 & 0.46 \\
\hline & c. Harga Jual & & & & & 18.500 & 100 & 17.000 & 70.83 \\
\hline & d. Margin pemasaran & & & & & 4.500 & 24.32 & 3.000 & 12.50 \\
\hline & e. Margin keuntungan & & & & & 4.389 & 23.72 & 2.889 & 12.04 \\
\hline & f. Rasio profit margin & & & & & 39.54 & & 26.02 & \\
\hline
\end{tabular}


Real Irhamna, dkk: Efisiensi Pemasaran Lanting di Desa Karang Anyar Kecamatan Gedong Tataan............

\begin{tabular}{|c|c|c|c|c|c|c|c|c|c|}
\hline \multicolumn{10}{|c|}{ Tabel 8. (Lanjutan) } \\
\hline \multirow[b]{2}{*}{ No } & \multirow[b]{2}{*}{ Uraian } & \multicolumn{2}{|c|}{ Saluran 1} & \multicolumn{2}{|c|}{ Saluran 2} & \multicolumn{2}{|c|}{ Saluran 3} & \multicolumn{2}{|c|}{ Saluran 4} \\
\hline & & $\mathrm{Rp} / \mathrm{Kg}$ & Share\% & $\mathrm{Rp} / \mathrm{Kg}$ & Share\% & $\mathrm{Rp} / \mathrm{Kg}$ & Share \% & $\mathrm{Rp} / \mathrm{Kg}$ & Share\% \\
\hline \multirow[t]{8}{*}{3} & Pedagang Pengecer & & & & & & & & \\
\hline & a. Harga & & & 17.000 & 70.83 & & & 17.000 & 70.83 \\
\hline & b. Biaya Simpan & & & 200 & 0.83 & & & 200 & 0.83 \\
\hline & c. Biaya kirim & & & 1.219 & 5.08 & & & 1.219 & 5.08 \\
\hline & d. Harga Jual & & & 24.000 & & & & 24.000 & 100 \\
\hline & e. Margin pemasaran & & & 7.000 & & & & 7.000 & 29.17 \\
\hline & f. Margin keuntungan & & & 5.581 & & & & 5.581 & 23.25 \\
\hline & g. Rasio profit margin & & & 3.93 & & & & 3.93 & \\
\hline \multirow[t]{7}{*}{4} & Harga Tingkat Konsumen & 17.500 & 100 & 24.000 & 100 & 18.500 & 100 & 24.000 & 100 \\
\hline & Total Biaya & 566 & 3.23 & 1.985 & 8.27 & 677 & 3.66 & 2.096 & 8.73 \\
\hline & Total Margin Pemasaran & 7.186 & 41.06 & 13.686 & 57.03 & 8.186 & 44.25 & 13.686 & 57.03 \\
\hline & Total Margin Keuntungan & 6.620 & 37.83 & 11.701 & 48.75 & 7.509 & 40.59 & 11.590 & 48.29 \\
\hline & Total RPM & 11.69 & & 5.89 & & 11.09 & & 55.2 & \\
\hline & Producer Share & & 100 & & 70.8 & & 775.7 & & 58.3 \\
\hline & $\begin{array}{l}\text { Rasio antara biaya pemasaran } \\
\text { dengan nilai penjualan produk }\end{array}$ & & 3.23 & & 8.27 & & 3.66 & & 8.73 \\
\hline
\end{tabular}

Sumber: Data primer diolah, 2020

Menurut Istiyanti et al., (2015) Efisiensi pemasaran emping melinjo diukur dengan producer share yaitu perbandingan antara harga di tingkat produsen dengan harga di tingkat konsumen dan rasio antara biaya pemasaran dengan nilai penjualan produk. Semakin besar nilai producer share akan semakin efisien saluran pemasaran. Sebaliknya semakin kecil rasio antara biaya pemasaran dengan nilai penjualan produk maka saluran pemasaran semakin efisien. Analisis efisiensi dengan hasil pengukuran menggunakan producer share, rasio antara biaya pemasaran dengan nilai penjualan produk dan analisis rasio profit margin serta margin pemasaran maka dapat disimpulkan bahwa saluran pemasaran yang paling efisien yaitu saluran pemasaran pertama dengan tanpa melibatkan lembaga perantara didalamnya yaitu dari produsen - konsumen akhir. Melihat perbandingan persentase pada setiap saluran, saluran pemasaran pertama merupakan saluran pemasaran dengan persentase terkecil yaitu $12,5 \%$ yang memiliki keterlibatan pelaku usaha produsen lanting dengan konsumen akhir didalamnya sedangkan pada saluran pemasaran ketiga dan keempat yang melibatkan pedagang pengepul memiliki persentase yang cukup besar yaitu $35 \%$ hal ini didukung dengan adanya kemudahan-kemudahan dari adanya pedagang pengepul. Adapun kemudahan yang dirasakan produsen yaitu memudahkan produsen dalam menjual produk lanting dalam artian pasar yang dituju untuk memasarkan produk yang diproduksinya sudah jelas akan permintaan produk setiap minggunnya dan dipermudah dengan adanya bantuan pemasokan bahan baku dari pengepul kepada produsen meski bantuan ini tidak terus menerus namun dirasa sedikit membantu produsen ketika terjadi kelangkaan bahan baku ataupun keterbatasan modal. Dengan demikian produsen harus lebih jeli untuk memilih saluran pemasaran yang ada, besar harapan untuk terus meningkatkan kerja sama antar kedua pihak yaitu produsen dan pengepul, agar produk lanting yang dihasilkan dapat lebih banyak lagi dan produk yang terjual dapat lebih luas jangkauan pemasarannya.

\section{KESIMPULAN}

Marjin pemasaran lanting di Desa Karang Anyar tertinggi berada pada saluran pemasaran kedua dan keempat yaitu Rp.13.686,-/kg serta yang paling rendah adalah saluan pertama yaitu Rp.7.186/kg dan keuntungan pemasaran tertinggi di saluran kedua yaitu sebesar Rp.11.710/kg . Saluran pemasaran yang paling efisien sesuai dengan pengukuran Producer Share, rasio antara biaya pemasaran dengan nilai penjualan produk, Ratio Profit Margin (RPM) dan margin pemasaran adalah saluran pemasaran yang tidak melibatkan lembaga pemasaran didalamnya yaitu produsen langsung ke konsumen akhir (saluran I). namun 
para produsen lebih memilih mmenggunakan saluran tiga dan empat karena menjalin kerjasama dengan kemudahan yang didaatkan seperti pnjualan produk, modal pinjaman alat produksi hingga bahan baku. Sehingga saran penulis pada penelitian ini yaitu kerjasama antara produsen lanting dan pedagang pengepul hendaknya lebih ditingkatkan, supaya para produsen dapat meningkatkan jumlah produksi dan pengepul dapat mengoptimalkan penjualan dengan melakukan inovasi melalui kemasan yang modern dan teknik promosi yang lebih luas untuk menarik minat dan selera para konsumen lanting.

\section{DAFTAR PUSTAKA}

Boneta, G. (2013) 'Pengaruh Produk, Harga, Promosi, dan Saluran Distribusi Terhadap Keputusan Pembelian Air Minum Dalam Kemasan Merek Aqua', Sekolah Tinggi Ilmu Ekonomi Bisnis Indonesia.

Dinas Koperasi dan UMKM (2020) Data pelaku UMKM Kabupaten Pesawaran. Provinsi Lampung.

Fitri, N. A., Apriyani, M. and Sari, A. (2017) Analisis Margin Pemasaran Cabai Rawit Merah di Kecamatan Lembang Kabupaten Bandung Barat. Politeknk Negeri Lamung.

Heriani, N., Zakaria, W. A. and Soelaiman, A. (2013) 'Analisis Keuntungan Dan Resiko Usaha Tani Tomat di Kecamatan Sumberejo Kabupaten Tanggamus’, Universitas Lampung, 1(2).

Istiyanti, E. et al. (2015) 'Efisiensi Pemasaran Emping Melinjo di Kabupaten Bantul Daerah Istimewa Yogyakarta', Universitas Muhammadiyah Yogyakarta.

Khairunnisa, T., Affandi, M. I. and Suryani, A. (2018) 'Analisis Efisiensi Pemasaran Emping Melinjo di Kelurahan Sukamaju Kecamatan Teluk Timur Kota Bandar Lampung', Jurnal Ilmu Ilmu Agribisnis, 6(4).

Mahdalena (2016) 'Tingkat Efisiensi Pemasaran Telur Itik Alabio dan Telur Asin di Kabupeten Hulu Sungai Utara. Provinsi Kalimantan Selatan', Sekolah Tinggi Ilmu Pertanian Amuntai, 6(2).

Sugiyono (2013) Metode Penelitian Pendidikan. Bandung: Afabeta.

Sukandarrumidi (2008) Metodologi Penelitian Petunjuk Praktis Untuk Peneliti Pemula. Yogyakarta: Gadjah Mada University Press.

Sutarno (2014) ‘Analisis Efisiensi Pemasaran Kedelai di Kabupaten Wonogiri’, Agrineca, 14(1).

Wulandari, D., Qurniati, R. and Herwati, S. (2018) 'Efisiensi Pemasaran Duriam (Durio zibethinus) di Desa Wisata Durian Kelurahan Sumber Agung', Sylva Lestari, 6(2).

Zuraida and Wahyuningsih, Y. M. (2015) 'Efisiensi Pemasaran Kacang Tanag (Arachis hypogeae L) di Kelurahan Landasan Ulin Tengah Kecamatan Landasan Ulin Kota Banjarbaru Provinsi Kalimantan Selatan', Ziraa'ah, 40(3). 